\title{
ПОТРЕБЛЕНИЕ ДИСКРЕЦИОННЫХ ПРОДУКТОВ ПИТАНИЯ: ЭКОЛОГИЧЕСКИЙ, ЭКОНОМИЧЕСКИЙ И СОЦИАЛЬНЫЙ КАРКАС
}

\author{
(c) 2019 Кравченко Алла Анатольевна \\ кандидат экономических наук, доцент, заведующая кафедрой мировой экономики \\ Дальневосточный федеральный университет, Россия, Владивосток
}

(c) 2019 Неяскина Елена Вячеславовна

кандидат экономических наук, доцент кафедры экономики

Морской государственный университет им. адм. Г.И. Невельского, Россия, Владивосток

E-mail: ekhlystova@yandex.ru

(c) 2019 Ухалова Татьяна Сергеевна

ст. преподаватель департамента экономических наук

Дальневосточный федеральный университет, Россия, Владивосток

\section{(c) 2019 Шишкарева Наталья Валерьевна}

кандидат экономических наук, доцент,

декан Факультета управления морским транспортом и экономики

Морской государственный университет им. адм. Г.И. Невельского, Россия, Владивосток

В данной статье рассмотрено потребление дискреционных продуктов питания через призму «устойчивого развития» и выделен каркас: экологический, экономический и социальный, который лежит в основе производства и потребления данной категории продуктов питания. С экологической точки зрения были выделены основные факторы, которые свидетельствуют о том, что производство и потребление дискреционных продуктов питания наносит значительный вред окружающей среде. С социальной точки зрения, дискреционные продукты питания являются питательно лишними и наносят вред здоровью человека. С экономической точки зрения, дискреционные продукты питания являются доступными для бедных слоев населения, однако чрезмерное употребление данных продуктов ведет к серьезным заболеваниям. На основе полученных результатов были сделаны выводы и даны рекомендации о необходимости сокращения производства и потребления дискреционных продуктов питания.

Ключевые слова: дискреционные продукты питания, правильное питание, выбросы $\mathrm{CO}_{2}$, окружающая среда

\section{Введение}

В современном мире потребление давно вышло за рамки экономической проблемы и стало достаточно сложным социокультурным образованием, что привело к изменению не только места и роли потребления в жизни общества, но и внутреннего содержания самого понятия потребления. Данные изменения проявляются в том, что потребление становится не просто процессом удовлетворения индивидом своих потребностей, а приобретает знаково-символический смысл. Глобальные изменения произошли и в сознании людей, в их поведении и отношении к самому процессу потребления. Данные изменения выражаются в том, что через процесс потребления индивид стремится самоидентифицироваться и самоутвердиться. В результате чего, потребности стали приобретать искусственный, а зачастую и извращенный характер. Главным потребительским свойством товара становится «новизна ради новизны», что приводит к потере объективной ценности данного товара. Основная проблема современного общества потребления заключается в том, что происходит перерождение рационального индивида в «человека потребляющего», который, по словам Э. Фромма, является «вечным сосунком с открытым ртом, вбирающим в себя без усилий и без внутренней активности все, что ни обрушивает на него индустрия...» (Фромм, 2014, С. 212-213). Потребитель в таком обществе выступает не целью производства, а средством извлечения экономической прибыли. Нехватка ресурсов приводит к тому, что производители, в погоне за высокой прибы- 
лью, ищут способы удешевления процесса производства. Особенно ярко данная тенденция находит свое отражение в производстве продуктов питания. Удешевление производства продуктов питания приводит к снижению их качества за счёт упрощения технологии, использования более дешёвых ингредиентов и усилителей вкуса. В результате потребитель получает такие продукты питания, которые содержат много соли, сахара, жиров, мало витаминов и обладают высокой калорийностью. Потребление подобных продуктов способно нанести серьезный ущерб здоровью потребителей. К таким продуктам питания относятся дискреционные продукты. Это такие продукты, которые не содержат в себе необходимых для организма веществ, но вносят разнообразие в рацион питания.

Чаще всего понятие дискреционные продукты встречается в современной зарубежной литературе и находит отражение в научных работах посвященных изучению «принципов правильного питания» (Johnson, Hendrie \& Golley, 2016. P. 1684; Batis et al., 2016. P. 1907; Nansel et al., 2016. P. 3; Cheval et al., 2017. P. 99; Hadjikakou, 2017. Р. 119). Также дискреционные продукты рассматриваются и в контексте обеспечения продовольственной безопасности, где авторы рассматривают эту категорию продуктов, как продукты с высокой энергетической ценностью (но бедные питательными веществами), что позволяет восполнять необходимый уровень ежедневного объема потребления калорий (Ruopeng, 2016. P. 28; Bleich et al., 2014. P. 28; Nansel et al., 2016. P. 4; Johnson, Hendrie \& Golley, 2016. P. 1685). Все чаще ученые рассматривают производство и потребление дискреционных продуктов питания с точки зрения их масштабного воздействия на экологию окружающей среды (Tassielli et al., 2017. P. 753; Hadjikakou, 2017. P. 119). Данная тенденция связана с тем, что с одной стороны, существующая практика производства продуктов питания способствует изменению климата, так как связана с негативным воздействием на окружающую среду. С другой стороны, излишнее потребление и большое количество пищевых отходов формируют «нездоровую» модель потребления в отношении экологии. Поэтому, в целях защиты здоровья населения и снижения экологического ущерба для планеты, а также в целях обеспечения продовольственной безопасности и безопасности питания необходимо перестраиваться на более устойчивые продовольственные системы.

Увеличение потребления пищевых продуктов растительного происхождения, снижение количества пищевых отходов, и сокращение потребления красного и обработанного мяса, продуктов, подвергшихся интенсивной технологической обработке, и газированных напитков с высоким содержанием сахара входят в рекомендации руководящих принципов правильного питания, представленных ФАО (Продовольственной сельскохозяйственной организацией объединенных нации) в концепции «устойчивого развития». В данной концепции, направленной на ликвидацию бедности, голода и одновременно на восстановление и рациональное использование природных ресурсов, выделяют три измерения устойчивого развития: экономическое, социальное и экологическое. В этой связи, мы рассматриваем потребление дискреционных продуктов питания через призму «устойчивого развития» и выделяем каркас: экологический, экономический и социальный, который составляет основу производства и потребления данной категории продуктов питания.

\section{Основные положения концепции}

Потребление дискреционных продуктов питания относится к необязательным (неосновным) покупкам, которые потребители хотят приобрести, но не те, которые им нужны. Как правило, расходы на такие виды покупок превышают обязательные минимальные расходы на элементарное обеспечение питания. При этом на решение о покупке влияют объективные экономические факторы (доходы, процент по потребительскому кредиту), а также психологические (промежуточные - в том смысле, что воздействие объективных экономических факторов на потребление идет через них) (Katona, 1975. Р. 438). В наиболее развитых странах дискреционное потребление является основной частью общего потребления индивидуума. K такому потреблению относится та часть потребления, в которой потребитель является зависимым от социального окружения. Таким образом, дискреционные продукты, по своей значимости для рационального потребителя являющиеся второстепенными, их в большей степени приобретают люди с низкой самооценкой, внутренне противоречивые и неуверенные в себе.

Дискреционные продукты - это продукты, которые не содержат в себе необходимые для 
организма вещества, но вносят разнообразие в рацион. Многие из этих продуктов содержат большое количество жиров, солей, сахара и/или алкоголя (Hadjikakou, 2017. Р. 119). Австралийская Ассоциация Диетологов (Australian Dietary Guidelines) определяет дискреционные продукты как неосновные продукты питания или как «вредная еда» («junk food»). Стоит обратить внимание на тот факт, что не все дискреционные продукты можно отнести к вредным. Так, например, дискреционные масло и сливки не всегда можно назвать вредными.

Также дискреционные продукты относят к продуктам питания с высокой энергетической плотностью, которые не обеспечивают необходимыми питательными веществами, в которых нуждается человеческий организм, но добавляют разнообразие в рационе питания. Дискреционные продукты не относятся ни к одной из основных групп и являются не обязательными в рационе питания (Ruopeng, 2016. Р. 28).

Дискреционные продукты питания - продукты с высоким содержанием насыщенных жиров, с добавлением сахара (HSFAS), соли и холестерина, которые пищевые нормативы советуют существенно сокращать в потреблении, но с низким содержанием способствующих здоровому питанию витаминов, минералов, клетчатки, а также сахаросодержащие напитки (SSB) (Bleich et al., 2014. Р. 28;). Данные продукты питания повышают вкусовые качества и могут вызывать привыкание (Nansel et al., 2016. Р. 3).

Дискреционные продукты - это высококалорийные, бедные питательными веществами продукты питания и напитки, содержащие насыщенные жиры, добавленный сахар, соль и алкоголь, которые не требуются в качестве части структуры питания (Johnson, Hendrie \& Golley, 2016. Р. 1684).

Проанализировав рассмотренные ранее определения «дискреционных продуктов», авторами было сформулировано и представлено определение, которое позволяет дать более четкую характеристику дискреционных продуктов и определить их как часть рациона питания, которая характеризуется высоким содержанием сахара, солей, жиров (Hadjikakou, 2017. P. 119; Bleich et al., 2014. Р. 72), обладающая высокой энергетической плотностью (Ruopeng, 2016. P. 28), бедная питательными веществами (Johnson, Hendrie \& Golley, 2016. Р. 1684), но являющаяся доступной и вносящая разнообразие в рацион питание (автор).
Примерами данной категории продуктов являются: продукты с высоким содержанием насыщенных жиров и/или добавленного сахаpa (HSFAS) (сливочное масло и сливки, обработанное мясо, колбаса и сосиски, картофельные чипсы, криспы, закуски с высоким содержанием калорий, а также торты и печенье, пироги и пирожные, кондитерские изделия, десерты, фруктовый лед и карамель), сахаросодержащие (SSB), энергетические, алкогольные напитки и др. (Hadjikakou, 2017. P. 119; Batis et al., 2016. Р. 1907; Ruopeng, 2016. Р. 28; Bleich et al., 2014. Р. 72).

Производство таких продуктов наносит значимый вред окружающей среде, при этом данная категория продуктов не представляет никакой ценности для организма человека с точки зрения медицинских норм потребления и напротив, являются питательно лишними. Из положительных сторон данной категории продуктов можно выделить их экономическую доступность для низких социально-экономических групп.

Рассматривая производство и потребление дискреционных продуктов питания через призму «устойчивого» развития выделим экологическую, экономическую и социальную составляющие каркаса. Для подтверждения достоверности факторов выделенных в качестве каркаса потребления дискреционных продуктов питания и тем самым, подтверждения достоверности наших выводов, проведем анализ данных представленных в статьях зарубежных авторов, а также статистических сборниках международных организаций и рассмотрим каждую составляющую предложенного каркаса в отдельности.

\section{Метод проведения анализа литературы}

При проведении исследования использовался контент-анализ, предполагающй качественно-количественный анализ содержания источников с целью выявления или измерения различных фактов и тенденций, отраженных в них. При анализе были рассмотрены работы зарубежных ученых посвященные изучению потребления дискреционных продуктов питания среди взрослого и детского населения (Ruopeng, 2016 P. 28; Bleich et al., 2014. Р. 72), их влияние на экологию, здоровье, дискреционные расходы, работы по экологической экономике, а также статистические сборники ФАО посвященные мониторингу продовольственной безопасности и устойчивому развитию и сборники Всемирного фонда дикой природы, посвященные индексу живой планеты. 


\section{Анализ}

Рассмотрим экологическую составляющую производства и потребления дискреционных продуктов питания.

Потребление продовольствия является одним из основных факторов воздействия на окружающую среду. С одной стороны, существует потребность в удовлетворении фундаментальных потребностей человека в питании, а с другой стороны, это создает критические угрозы для окружающей среды (Tassielli et al., 2017. P. 753). В процессе потребления возникают разного рода негативные экологические внешние эффекты, которые, в свою очередь, могут стать одной из причин экологического кризиса. Особенно это относится к неумеренному производству и потреблению дискреционных продуктов (рисунок 1).

Для понимания масштабов экологических проблем, связанных с потреблением, и важности изучения экологичного потребления, приведём некоторые статистические факты.

Производство дискреционных продуктов связано с ухудшением качества почвы и воды, загрязнением атмосферы и потерей биоразнообразия. Высокий уровень потребления дискреционных продуктов обуславливает высокий уровень их производства, что в свою очередь вызывает большой объем образования сточных вод на предприятиях, при этом они имеют высокую степень загрязненности и представляют опасность для окружающей среды. Сброс сточных вод в водоемы быстро истощает запасы кислорода, что вызывает гибель обитателей этих водоемов (Grieger et al., 2016).

Существует сильная связь между выбросом парниковых газов, связанной с питанием, и потреблением энергии. Углекислый газ, выбрасываемый отходами от производства дискреционных продуктов используется на 10-20\%, остальное выбрасывается в атмосферу, усиливая парниковый эффект (Grieger et al., 2016).

Воздействие дискреционных продуктов на окружающую среду на протяжении всего жизненного цикла значительно больше воздействия не дискреционных. Так, при производстве 1 т кукурузных чипсов объемы выбросов СО2 в окружающую среду составят 1300 кг, а потребление пресной воды -3 млн. л, что в разы превышает аналогичные показатели при производстве продуктов питания, которые являются «сырыми», например на производство 1 т пшеницы объемы выбросов СО2 в окружающую среду составят 300-400 кг, а потребление пресной воды - 0,13 млн. л (1 т томатов: CO2-300 кг, Н2О - 0,214 млн. л). Производство обработанного мяса, приправ и кондитерских изделий оказывает более негативное воздействие на окружающую среду, при этом довольно значительные выбросы также поступают из производства хлебобулочных изделий и алкоголя (Australian National University, 2011).

Дискреционные продукты составляют 3339\% пищевых продуктов в воздействии на окружающую среду (экологический след) (Hadjikakou, 2017. Р. 119). В среднем на дискреционные продукты приходится $35 \%$ общего потребления воды, 39\% потребления энергии, 33\% выбросов

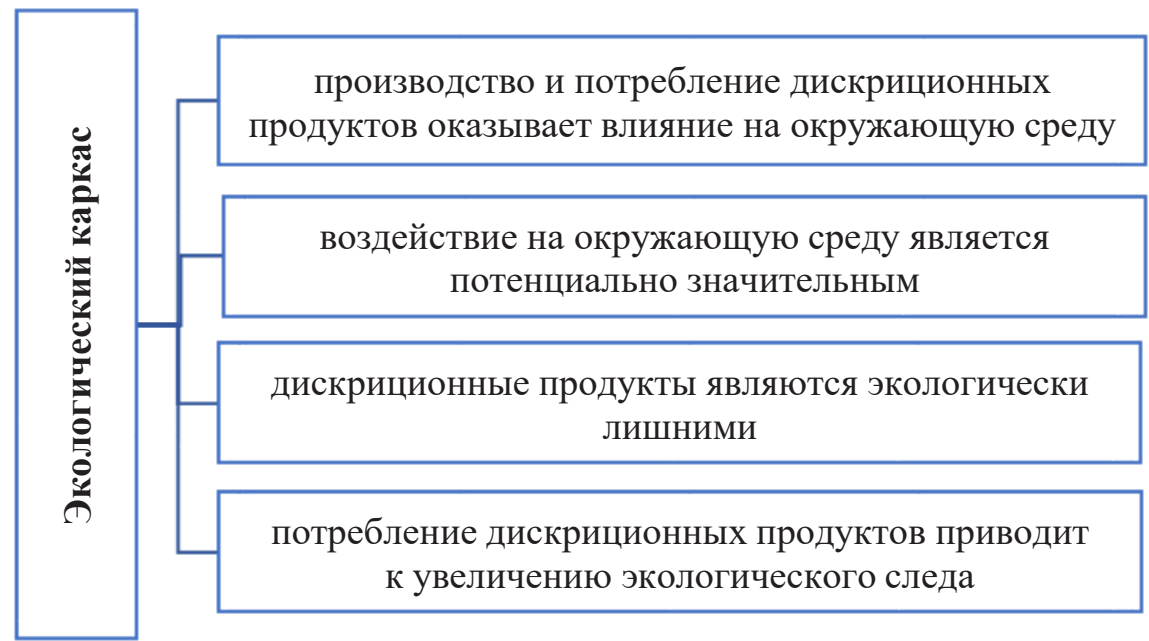

Puc. 1. Экологическая составляющая производства и потребления дискреционных продуктов Источник: составлено авторами 
CO2 и 35\%, использования земли. Столь большие проценты должны послужить стимулом для ограничения в будущем потребления дискреционных продуктов, включая полный отказ от них.

Дискреционные продукты оказывают пагубное воздействие на окружающую среду. Это утверждение подтверждается вышеприведенными данными по объемам выбросов углерода и объемам затраченной пресной воды при производстве данной категории продуктов. Также стоит отметить, что данная группа продуктов питания не несет ценности для организма человека, они высококалорийны, но не содержат в себе питательных элементов. Исходя из этого, мы можем сделать вывод, что эти продукты являются экологически лишними, т.к. наносят больше вреда окружающей среде, чем другие категории продукты питания и в тоже время представляют гораздо меньше ценности для организма человека.

На протяжении более 40 лет потребление человеком природных ресурсов опережает способность планеты к их воспроизводству. Экологический след - площадь, необходимая для производства используемых природных ресурсов и экосистемных услуг, превышает биоемкость планеты - фактически имеющуюся площадь, способную производить эти ресурсы и услуги. В настоящее время для воспроизводства природных ресурсов и поддержания экосистемных услуг, используемых человечеством ежегодно, необходим потенциал полутора планет Земля. Неизбежным следствием этого является сокращение запасов ресурсов и накопление отходов темпами, превышающими способность планеты к их поглощению или переработке, что приводит, например, к росту концентрации углекислого газа в атмосфере. На 2014 г. крупнейшей составляющей экологического следа человечества являлся углеродный след (53\%) (World Wildlife Fund, 2014).

Немало важную роль в формировании экологического следа, в частности углеродного следа, занимает сельское хозяйство. Так, повышение биоемкости сельскохозяйственных земель за счет механизации и использования удобрений требует большего потребления ископаемого топлива, что ведет к увеличению углеродного следа. Ранее мы уже сделали вывод о том, что выбросы углерода от производства дискреционных продуктов в разы превышают объемы выбросов от недискреционных.
Таким образом, можно утверждать, что производство дискреционных продуктов, оказывает больше влияния на размеры экологического следа, чем производство недискреционных продуктов, что еще раз подтверждает пагубное воздействие на экологию от производства данной категории продуктов питания.

Рассмотрим экономическую составляющую производства и потребления дискреционных продуктов.

Современный мир сталкивается не только с проблемой голода, но и с проблемой нездорового рациона питания, что делает данную проблему одной из самых актуальных в настоящее время. Столь пристальное внимание к данной проблеме со стороны различных ученых и мирового сообщества объясняется тем, что нарушения питания не только оказывают отрицательное воздействие на организм человека, но и является частью проблемы благосостояния общества. Данные организации подчеркивают, что в сложившихся условиях назрела необходимость реформирования продовольственных систем, с целью создания условий для обеспечения пищевого разнообразия, здорового питания и экологической устойчивости.

В экономической составляющей потребления дискреционных продуктов можно выделить два аспекта. С одной стороны, дискреционные продукты являются доступным и удобным вариантом для потребителей. Удобство потребления таких продуктов объясняется, во-первых: нехваткой времени для приготовления пищи. Во-вторых, дискреционные продукты могут долго оставаться свежими в результате наличия в них консервантов. Доступность дискреционных продуктов для потребителя объясняется их дешевизной, которая объясняется тем, что при производстве данных продуктов происходит замена дорогих натуральных ингредиентов, на более дешевые заменители. Помимо ценовой составляющей доступности дискреционных продуктов можно отметить, что производители данных продуктов питания активно продвигают их посредством рекламных кампаний и акций, часто ориентированных на более низкие социально-экономические слои населения и все чаще на потребителей в развивающихся странах.

К экономической составляющей производства дискреционных продуктов можно отнести их высокую степень рентабельности (рисунок 2). Для производителей, дискреционные продукты 
более дешевые в производстве (синтетические аналоги дешевле, чем натуральные компоненты), но более прибыльны из-за объемов их потребления.

Так, исследования австралийского национального университета позволили сделать вывод, что группы населения с низким уровнем дохода потребляют намного больше дискреционных продуктов, чем группы населения со среднем и высоким уровнем дохода (рисунок 3) (Australian National University, 2011).

Из рисунка 3 видно, что группы населения с высоким уровнем дохода ежедневно потребляют больше продуктов, чем группы со средним и низким доходами, однако процент ежедневного потребления дискреционных продуктов относи- тельно общего потребления меньше, чем у групп со средним и низким доходами.

Второй аспект экономической составляющей потребления дискреционных продуктов связан с тем, что сверхпотребление данной группы продуктов питания наносит вред здоровью потребителей. Многочисленные научные исследования, посвященные данному вопросу, показали, что потребление дискреционных продуктов напрямую связано с увеличением случаев болезни сердца, диабета, ожирения, инсульта и некоторых форм рака.

В свою очередь здоровье, как подтверждают обширные исследования, является своего рода индикатором качества жизни и благосостояния общества. Плохое здоровье приводит к разного

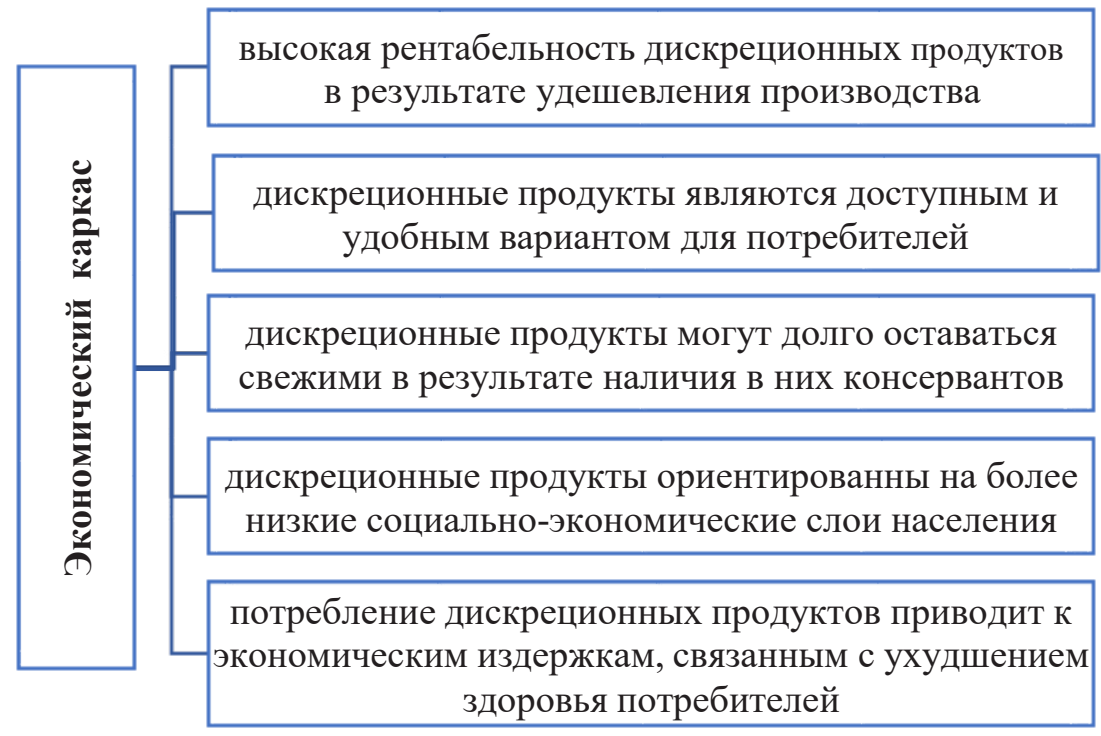

Puc. 2. Экономическая составляющая производства и потребления дискреционных продуктов Источник: составлено авторами

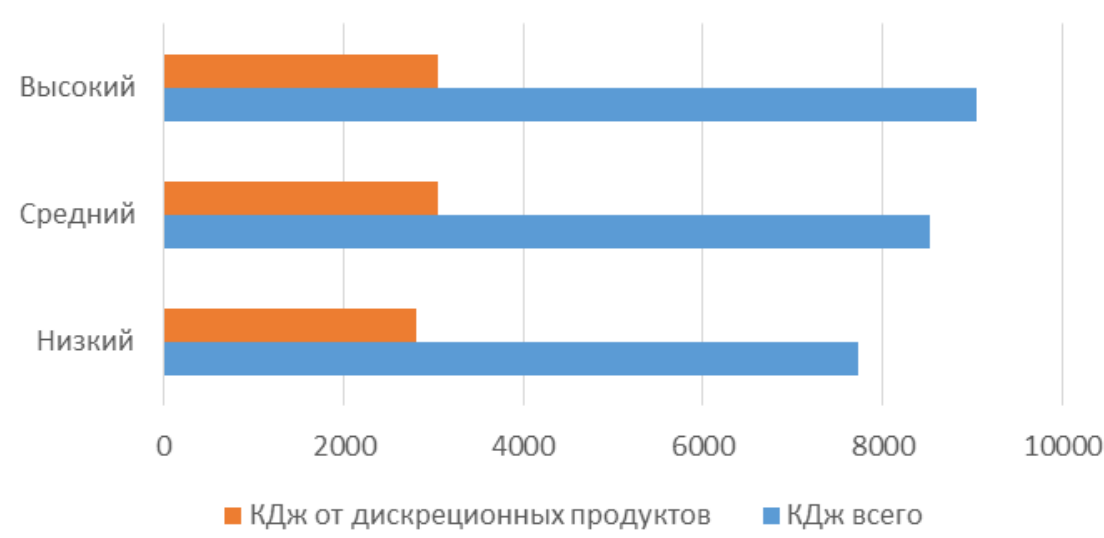

Рис. 3. Зависимость среднего ежедневного потребления дискреционных продуктов от уровня дохода Источник: составлено авторами по (Gonzalez Fischer, Garnett \& Plates, 2016) 
рода экономическим издержкам. Данные издержки могут возникать и на уровне отдельных граждан и их семей, а так же на уровне экономики в целом. В первом случае экономические издержки связаны с тем, что плохое здоровье приводит к снижению работоспособности граждан, уменьшению заработной платы и увеличению затрат на приобретение медикаментов. Во втором случае речь идет о том, что плохое здоровье членов общества снижает общественное благосостояние.

Рассмотрим социальную составляющую производства и потребления дискреционных продуктов.

В условиях трансформации общества, питание, являясь одной из главных потребностей человека, претерпело существенные изменения. Данные изменения связаны с тем, что питание современного человека выходит далеко за рамки физиологической потребности и становится важным социальным и культурным процессом. «Питание занимает особое место в описании специфики вида Homo sapiens потому, что наряду с сохранением функций, свойственных любому другому виду, оно стало одной из фундаментальных культурных характеристик человечества». В то же время существенный отпечаток на модели питания накладывают социальные процессы, происходящие в обществе. Мы живем в эпоху стремительного развития человеческой цивилизации, в которой происхо- дит ускорение темпа жизни. На приготовление и прием пищи в сложившихся условиях просто не хватает времени. В результате питание большинства людей состоит из перекусов, в перерывах между делами и т.д. Поэтому на сегодняшний день для большинства потребителей вкус, стоимость и удобство считаются более важными, чем качество, полезность и натуральность. Именно поэтому большинство потребителей выбирают дискреционные продукты (рисунок 4).

Потребление дискреционных продуктов очень удобно для потребителей. Как правило, они не требуют приготовления и представляют собой готовую еду, что очень актуально в современном мире. Все это приводит к тому, что на смену вековых традиций семейного приема пищи приходит культура перекуса и питание вне дома. Другими словами, в обществе происходит существенное изменение культуры потребления, которая определяет качества потребления: что потреблять и для чего потреблять.

K социальной составляющей потребления дискреционных продуктов можно отнести и то, что некоторые из этих продуктов, несмотря на их явное отрицательное влияние на здоровье, являются неотъемлемой частью комфорта, удовольствия и представляют некоторую культурную ценность для потребителей. Поэтому дискреционные продукты можно отнести к гедонистическим продуктам, которые предназначены для получения удовольствия.

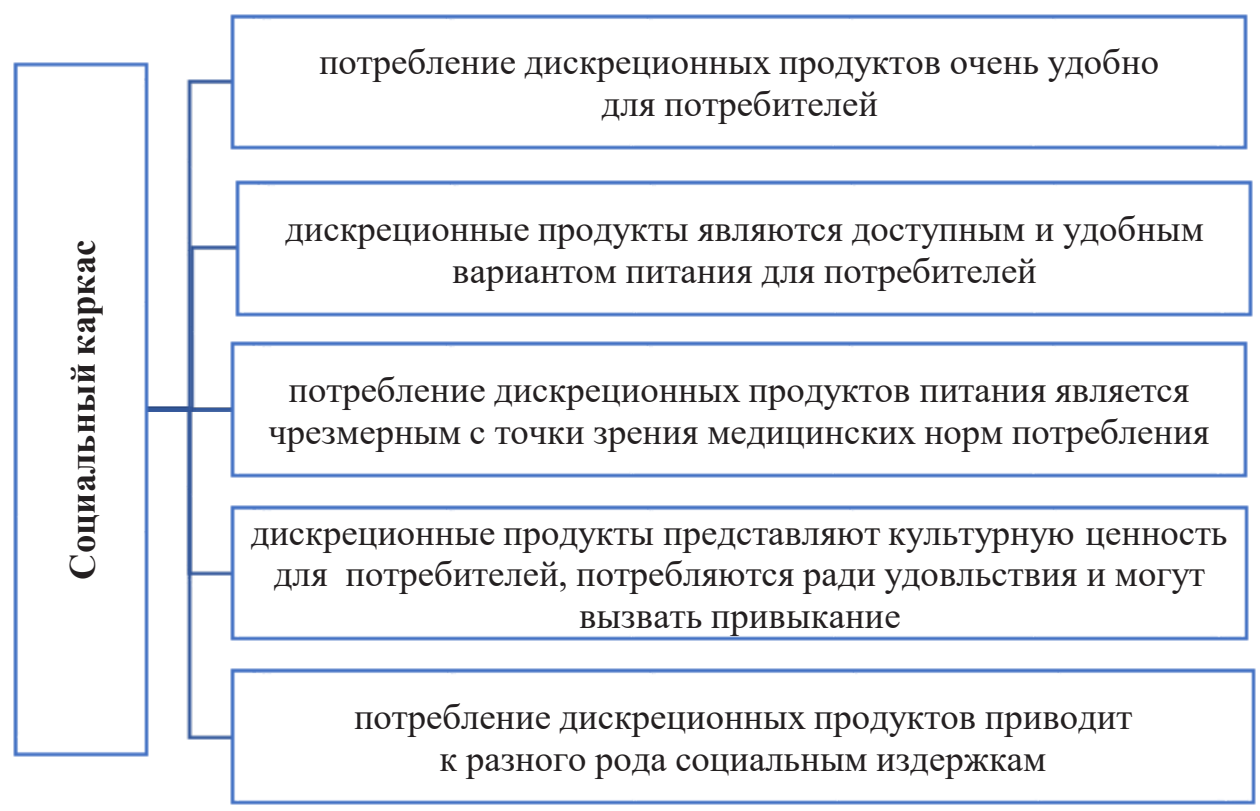

Рис.4. Социальная составляющая производства и потребления дискреционных продуктов Источник: составлено авторами 
Ряд исследователей, занимающихся гедонистическим потреблением, связывают его с роскошью. Так, А. Chernev (2004) определяет гедонистическое потребление как покупку чего-то ненужного для функционирования жизнедеятельности. Другой исследователь использует термин «роскошное потребление» для обозначения того, что люди потребляют сверх нормы калорий для своего обмена веществ (Hadjikakou, 2017. Р.120).

Потребление дискреционных продуктов является чрезмерным с точки зрения медицинских норм потребления, что так же можно отнести к социальной составляющей потребления данных продуктов. Как отмечалось ранее, дискреционные продукты вносят разнообразие в рацион питания, имеют высокую энергетическую ценность, удобны в потреблении. Но в то же время такое питание является не правильным и наносит существенный вред здоровью потребителей, вызывая различные неинфекционные заболевания, являющиеся основной причиной преждевременной смертности - не только в странах с высоким уровнем дохода, но и во многих странах развивающегося мира. Как следствие, плохое здоровье приводит к увеличению социальных издержек, которые показывают, насколько высоко люди ценят свое здоровье. Чем больше люди задумываются над тем, что они едят и каковы последствия потребления тех или иных продуктов питания, тем выше продолжительность жизни и ниже социальные издержки. Чем выше продолжительность жизни, тем больший доход принесет человеку здоровая и продуктивная жизнь.

\section{Обсуждение}

Анализ результатов научных исследований авторов, занимающихся проблемой потребления дискреционных продуктов, а также данных международных организаций, занимающихся вопросами продовольственной безопасности и защиты окружающей среды, показал, что факторы, рассмотренные в качестве основных критериев экологического, экономического и социального каркаса потребления дискреционных продуктов находят статистическое подтверждение.

Исследования подтверждают, что потребление дискреционных продуктов как части ежедневного рациона питания значительно влияет на энергетический баланс и общее состояние здоровья населения (Ruopeng, 2016. Р. 30). Чрезмерное потребление дискреционных продуктов связано с повышенным риском ожирения, сердечно-сосудистых заболеваний, диабета второго типа, некоторых видов рака и кариеса. Риск этих хронических заболеваний начинается в детстве и отслеживается во взрослой жизни.

Это вызывает особую озабоченность ввиду значительного хронического бремени болезней и высоких показателей ожирения на протяжении всей жизни. Переизбыток дискреционных продуктов также может вытеснять основные продукты питания (фрукты, овощи, молочные продукты, постное мясо, цельные зерна) из рациона, что еще больше увеличивает риск дефицита питательных веществ, ожирения и хронических заболеваний. Так как данная группа продуктов питания не несет ценности для организма человека, они высококалорийны, и не содержат в себе питательных элементов, то должны рассматриваться только как «дополнительные продукты» в контексте получения энергии. Потребление дискреционных продуктов становится все более распространенным явлением, свидетельствующим о том, что стоимость здоровой пищи растет быстрее, чем стоимость перерабатываемой пищи, в особенности в странах с высоким доходом, как США и Великобритания, а также в странах с переходной экономикой, таких как Бразилия, Мексика и Китай. Таким образом, дискреционные продукты чаще употребляются более бедными социально-экономическими группами населения (Hadjikakou, 2017. Р. 120). Помимо этого, существует вязь между общей потребляемой энергией от дискреционной пищи и условиями питания (время приема пищи, активность и место) (Batis et al., 2016. Р. 1910). Дискреционные продукты - доступный и удобный вариант продуктов питания для потребителей.

На нездоровое потребление высококалорийных продуктов питания косвенное влияние оказывает голод (чувство голода), так как положительно влияет на стимулирующую ценность (или «желание») в потреблении. Такому влиянию подвержены в большей степени люди, которые не следят за своим здоровьем, и в меньшей степени те, кто склонен потреблять в основном здоровую пищу (Cheval et al., 2017. Р.100). Это подтверждает необходимость поощрения более здорового выбора продуктов питания среди населения, особенно во время перекуса, просмотра телевизора, а также улучшения пищевых усло- 
вий на работе, в образовательных учреждениях и на улице.

Следует признать, что потребление дискреционных продуктов приносит удовольствие от еды, часто в контексте социальной деятельности или семейных и культурных мероприятий. Повышенная чувствительность к пищевым продуктам связана с более частым потреблением дискреционных продуктов среди молодежи. Если повышенная чувствительность к пище увеличивает потребление из-за гедонистической еды (еда для удовольствия в отсутствие энергетической потребности), это говорит о том, что такое не гомеостатическое пищевое поведение, скорее всего, будет нацелено на продукты с наибольшей гедонической ценностью. Дополнительные исследования, разъясняющие влияние индивидуальной восприимчивости на воздействие пищевых продуктов на пищевое поведение, могут помочь в развитии вмешательств, направленных на улучшение качества питания (Nansel et al., 2016. P. 24).

Основным фактором деградации окружающей среды является не само по себе население, а его структура потребления и уровни, умноженные на количество потребителей. Окружающую среду, способствующую развитию ожирения, можно охарактеризовать как создающую условия для широкой доступности и, как следствие, высокого уровня потребления высококалорийных продуктов питания в условиях глобализированной экономики в сочетании с ростом распространенности сидячего образа жизни.

Анализ показал, что потребление дискреционных продуктов связано с различными воздействиями на окружающую среду, поэтому выбор продуктов питания потребителями представляет собой важные экологические решения.

Потребление продуктов питания является существенной движущей силой экологического дефицита планеты, в результате чего спрос на возобновляемые ресурсы и услуги в области экосистем опережает возможности его экосистем для их обеспечения. На долю продовольствия приходится большая часть экологического следа. Снижение потребления высококалорийных продуктов питания и переход на более здоровую диету способны не только повысить качество питания, а, следовательно, и уровень здоровья населения, но и уменьшить экологический след на 8-10\% (Galli et al., 2017. P. 383).

Сокращение потребления калорий и пище- вых отходов уменьшает экологическую нагрузку на продукты питания. Таким образом, сокращение потребления калорий может повлечь за собой как умеренность диет, так и сокращение отходов путем повышения эффективности изменения предложения, а также изменения в пищевом поведении населения.

Учитывая то, что данная категория продуктов не входит в рекомендуемый рацион питания, к которому ФАО призывает в руководящих принципах питания (Food and Agriculture Organization of the United Nation, 2017), необходимо принимать конкретные меры для поддержки более устойчивых моделей потребления и производства.

\section{Рекомендации}

В связи с вышесказанным можно уверенно заявить, что проблема улучшения здоровья населения, пропаганда здорового образа жизни, и как следствие этому повышение благосостояния в целом, является актуальной экономической, социальной и политической проблемой. И решаться данная проблема должна на государственном уровне. Производители продуктов питания должны, в свою очередь, нести ответственность за распространение дешевой дискреционной пищи. Правительство должны поощрять отказ от нездоровой, неустойчивой продукции посредством регулирования и давления со стороны общественности, следуя примеру мер по борьбе с изменением климата.

Можно выделить следующие инструменты воздействия государства на рацион питания и на продовольственную среду: экономические, неэкономические и административные.

$\mathrm{K}$ экономическим инструментам можно отнести: налоги, цены и денежные доходы населения. Используя данные инструменты, государство может воздействовать на выбор потребителя и на структуру потребления в целом.

$\mathrm{K}$ неэкономическим инструментам можно отнести рекомендательную политику государства в области: пропаганды здорового образа жизни; культуры питания; рационального потребления продуктов питания; информированности о влиянии потребления дискреционных продуктов на здоровье.

K административным инструментам можно отнести: запрет рекламы в средствах массовой информации дискреционных продуктов; обязательную маркировку продуктов питания 
с указанием потенциального вреда здоровью используемых ингредиентов; запрет продажи продуктов питания потенциально вредных для здоровья.

Достаточно распространенной мировой практикой воздействия на рацион питания населения является налог на разные группы дискреционных продуктов. Данная мера существует в ряде развитых стран, таких как США, Франции, Дании, Венгрии, Египте, Финляндии, Мексике, Тайланде и т.д. Введение подобной меры может давать как экономический, так и социальный эффект. Социальный эффект выражается в улучшении здоровья населения. Экономический - в получении дополнительных доходов в бюджет страны от сборов с продаж дискреционных продуктов (Таблица 1).
Как показывают данные Таблицы 1 введение налога на некоторые группы дискреционных продуктов оправдало себя и привело к изменению пищевого поведения населения, а также способствовало увеличению доходной части бюджета стран. Вместе с тем, в некоторых странах отсутствуют данные, подтверждающие медико-социальный эффект от введения налогов на дискреционные продукты. Это объясняется недостатком исследований в данной области. Несмотря на то, что введение налога привело к положительному экономическому и социальному эффекту, Европейский союз принял против налога ряд санкций и он был отменен в Дании и Эквадоре. Отмена налога объясняется отсутствием четких критериев отнесения продуктов питания к вредным для здоровья и не подготов-

Таблица 1. Налог на разные группы товаров дискреционных продуктов в развитых странах

\begin{tabular}{|c|c|c|c|}
\hline Объект налогообложения & Страна & Размер налога & Эффект \\
\hline $\begin{array}{l}\text { 1. Вес жира и жир, исполь- } \\
\text { зуемый при производстве } \\
\text { продуктов питания; } \\
2 . \text { Продукты с содержанием } \\
\text { насыщенных жиров свыше } \\
2,3 \% .\end{array}$ & $\begin{array}{l}\text { Дания } \\
\text { 2011-2013 гг. }\end{array}$ & $\begin{array}{l}2,5 \text { евро на } 1 \text { кг насыщенных } \\
\text { жиров } \\
\text { НДС } 25 \%\end{array}$ & $\begin{array}{l}\text { улучшение здоровья населе- } \\
\text { ния }\end{array}$ \\
\hline $\begin{array}{l}\text { 1. Безалкогольные сладкие } \\
\text { напитки; } \\
\text { 2. Конфеты и шоколад. }\end{array}$ & $\begin{array}{l}\text { Финляндия } \\
2011 \text { г. }\end{array}$ & $\begin{array}{l}0,95 \text { евро с килограмма моро- } \\
\text { женного или конфет; } \\
0,11 \text { евро с литра безалкоголь- } \\
\text { ных напитков;. } \\
\text { Для напитков с содержанием } \\
\text { сахара более } 0,5 \% \text { была уста- } \\
\text { новлена ставка в } 0,22 \text { евро }\end{array}$ & $\begin{array}{l}\text { - дополнительные доходы } \\
\text { для бюджета; } \\
\text { - данных о влиянии сборов } \\
\text { на здоровье населения не } \\
\text { собирается. } \\
\text { - падение потребления } \\
\text { сахара и сахаросодержащих } \\
\text { напитков. }\end{array}$ \\
\hline Сладкие напитки & Франция & $\begin{array}{l}7,5 \text { евро с гектолитра сладких } \\
\text { напитков }\end{array}$ & $\begin{array}{l}\text { - дополнительные доходы } \\
\text { для бюджета (300 млн. евро в } \\
\text { год); } \\
\text { - снижение потребления } \\
\text { сладких напитков среди моло- } \\
\text { дежи и населения с низким } \\
\text { уровнем дохода } \\
\text { - сокращение производите- } \\
\text { лями ингредиентов неблаго- } \\
\text { приятно воздействующих на } \\
\text { здоровье }\end{array}$ \\
\hline $\begin{array}{l}\text { Сахар, соль и метилксан- } \\
\text { тины в подготовленных к } \\
\text { упаковке продуктах }\end{array}$ & $\begin{array}{l}\text { Венгрия } \\
2011 \text { г. }\end{array}$ & $\begin{array}{l}\text { акциз на содержание сахара, } \\
\text { соли и метилксантинов (к ним } \\
\text { относится, кроме прочего, } \\
\text { кофеин) в подготовленных к } \\
\text { упаковке продуктах }\end{array}$ & $\begin{array}{l}\text { - снижение объемов покупок } \\
\text { на 25-30\% } \\
\text { - сокращение производите- } \\
\text { лями ингредиентов неблаго- } \\
\text { приятно воздействующих на } \\
\text { организм }\end{array}$ \\
\hline $\begin{array}{l}\text { 1. Сахаросодержащие на- } \\
\text { питки; } \\
\text { 2. Снеки, и другие продукты } \\
\text { с содержанием какао, моро- } \\
\text { женое, пудинги, конфеты и } \\
\text { арахисовое масло (продук- } \\
\text { ты с калорийностью выше } \\
275 \text { ккал на } 100 \text { грамм) }\end{array}$ & $\begin{array}{l}\text { Мексика } \\
2014 \text { г. }\end{array}$ & $\begin{array}{l}1 \text { песо на } 1 \text { литр (10\%) } \\
8 \% \text { к розничной цене }\end{array}$ & $\begin{array}{l}\text { снижение потребления дан- } \\
\text { ной группы товаров от } 12 \text { до } \\
17 \%\end{array}$ \\
\hline
\end{tabular}

Источник: составлено авторами 
ленностью общества к введению данного налога.

Поскольку дискреционные продукты потребляются чаще всего населением с низким уровнем доходов, то можно выделить еще одну экономическую меру в борьбе за здоровье населения - повышение покупательной способности потребителей. К основным методам повышения покупательной способности можно отнести: политику государства в области формирования и распределения денежных доходов; функционирование системы социальной защиты. Данные меры имеют прямое воздействие на структуру потребления и качество питания.

Хотелось бы отметить, что использование вышеперечисленных инструментов воздействия государства на рацион питания и на продовольственную среду принесет ожидаемый экономический и социальный эффект только в том случае, если они будут использоваться в совокупности. Не возможно решить проблему потребления вредных продуктов только запретами или, напротив, экономическими или неэкономическими инструментами. Как показывает практика, «запретительные» законы не приводят к сокращению числа потенциальных покупателей, а могут увеличить рынок нелегальной продукции, что нанесет еще больший вред здоровью населения. И пока органы власти выбирают какой из инструментов применять, производители продолжают активно продвигать вредные продукты питания. По нашему мнению любые регулирующие решения со стороны государства, должны быть безопасными и достижимыми. Например, Международная ассоциация снижения вреда (IHRA) предлагает концепцию «снижения вреда» в качестве основного метода, направленного на сокращение последствий, связанных с потреблением продукции, способной причинить вред. В основе данной концепции лежит понимание того, что большинство людей не могут или не хотят прекратить потреблять вредную продукцию по разным причинам. В силу этого данный метод учитывает потребности людей и основан не на принуждении и запрете, а на содействии. Согласно статистическим данным IHRA, предложенная ими концепция является эффективным, осуществимым, практичным, безопасным, а самое главное, экономически целесообразным решением. Исходя из всего вышесказанного очевидно, что без участия государства и его соответствующей политики проблему качества питания не решить.
Как говорит директор департамента питания в области здоровья и развития ВОЗ д-р Франческо Бранка: «Страны должны задуматься о том, как они руководят системой питания. Это означает работу в нескольких направлениях, включая сельское хозяйство, производство продуктов питания, распределение и розничную торговлю, здравоохранение, социальное благосостояние и образование».

\section{Заключение}

Данная статья утверждает, что сокращение производства и потребления дискреционных продуктов является важнейшей частью устойчивости продовольственной системы и первым шагом в направлении улучшения и сохранения здоровья людей и экологии планеты. Сокращение производства и потребления дискреционных продуктов позволило бы снизить объемы выбросов углерода в атмосферу и снизить объемы потребления питьевой воды, т.к. производство основных продуктов питания, оставляет меньший экологический след (в частности производство овощей, молочных продуктов и зерна), тем самым это могло бы обеспечить рост питательной выгоды при незначительных экологических затратах. В связи с этим, возникает необходимость подвергнуть сомнению массовое производство и распространение дискреционных продуктов и непрерывный целенаправленный маркетинг для более низких социальноэкономических групп населения и детей. Задача состоит в том, чтобы обеспечить равные возможности для всех социально-экономических групп населения таким образом, чтобы семьи, живущие с низким доходом, делали свой выбор в пользу окружающей среды, но вместе с этим основное внимание уделялось улучшению качества питания.

В этой связи представляется целесообразным создание такой системы, которая с одной стороны позволяла бы развивать предпринимательство в сфере продовольствия, с другой стороны сохраняла людям здоровье и окружающую среду. Так, в дискуссионном документе «Оценка воздействия мер политики на формирование здоровой продовольственной среды и оздоровление рациона питания» сказано, что «продовольственные системы влияют на то, какие пищевые продукты физически и финансово доступны, удобны и желательны для человека, то есть на продовольственную среду. Продо- 
вольственная среда в сочетании с отдельными факторами, такими как доход, знания, время и предпочтения, влияет на рацион питания. В свою очередь, рацион питания определяет пищевой статус и уровень риска неинфекционных заболеваний (НИЗ)» (UNSCN Quarterly Newsletter, 2017). Очевидным является тот факт, что необходимо проводить дальнейшие исследования в этой области, направленные на переход к устойчивому рациону питания и заменять дискреционные пищевые продукты с целью минимизации экологических и социальных последствий при максимальном качестве питания, особенно среди более бедных социально-экономических групп населения.

\section{Библиографический список}

1. Всемирный фонд дикой природы, 2014. Доклад WWF «Живая планета 2014». URL http://www.ecoindustry.ru/ gosdoklad/view/280.html

2. Козловская M.B. (2002). Феномен питания в эволюции и истории человека. PhD Thesis. Moscow: Институт Археологии РАН. [Kozlovskaya M. V. (2002). Fenomen pitaniya v evolyutsii i istorii cheloveka. PhD Thesis. Moscow: Institut Arkheologii RAN. (In Russian).]

3. Лисневский, Д.Э. (2013). Воздействие поведения потребителя на цикличность экономического развития. PhD Thesis. Moscow: Московский государственный университет имени М.В. Ломоносова. [Lisnevskiy, D.E. (2013). Vozdeystvie povedeniya potrebitelya na tsiklichnost' ekonomicheskogo razvitiya. PhD Thesis. Moscow: Moskovskiy gosudarstvennyy universitet imeni M.V. Lomonosova. (In Russian).]

4. Мир начал борьбу против рекламы нездоровой пищи (2008, март 16). In RBC, общество. Retrieved June 10 , 2017, URL http://www.rbc.ru/society/16/03/2008/5703cba59a79470eaf769b54

5. Руководящие принципы правильного питания на основе имеющихся продуктов. In FAO. Retrieved June 10, 2017, URL http://www.fao.org/nutrition/education/food-dietary-guidelines/background/sustainable-dietaryguidelines/ru/

6. ФАО (2012). Биоразнообразие и устойчивые рационы питания: направления и решения для политики, исследований и действий. Доклад технического совещания по биоразнообразию и устойчивым рационам питания, 3 мая - 1 июня 2010 года, Рим. URL http://uchebana5.ru/cont/1118828.html

7. ФАО, МФСР и ВПП. (2016). Мониторинг продовольственной безопасности и питания в поддержку осуществления Повестки дня в области устойчивого развития на период до 2030 года: подведение итогов и планы на будущее. Рим, ФАО. http://www.fao.org/3/a-i6188r.pdf

8. Фромм, Э. (2014). Революция надежды / пер. с анг. - М.: АСТ, 2014. - 212-213 с. [Fromm, E. (2014). Revolyutsiya nadezhdy / per. s ang.-M.: AST, 2014.- pp. 212-213. (In Russian).]

9. Allman-Farinelli, M., Roy, R, Rangan, A., Hebden, L., Jimmy, Chun Yu Louie, Lie, Ming Tang, \& Kay, J. (2017). Dietary contribution of foods and beverages sold within a university campus and its effect on diet quality of young adults. Nutrition, 34, pp. 118-123.

10. Batis, C, Rodríguez-Ramírez, S, Ariza, A.C, \& Rivera, J.A. (2016). Intakes of Energy and Discretionary Food in Mexico Are Associated with the Context of Eating: Mealtime, Activity, and Place. J Nutr., 146(9), pp. 1907-1915.

11. Biodiversity and sustsinable diets united against huger: Proceedings of the International Scientific Symposium 2010, Novemder, 3-5 (2012). In FAO Headquarters, Rome. Retrieved June 10, 2017, URL http://www.fao.org/ docrep/016/i3004e/i3004e.pdf

12. Bleich, C.H., Wolfson, JA, Vine, S, \& Ван, YC. (2014). Diet-Beverage Consumption and Caloric Intake Among US Adults, Overall and by Body Weight. American Journal of Public Health, 104(3), pp. 72-78.

13. Bradbear $C$ and Friel $S$ (2011). Food systems and environmental sustainability: A review of the Australian evidence. NCEPH Working Paper. Canberra: Australian National University. URL http://nceph.anu.edu.au/files/ Food\%20systems\%20and\%20Environmental\%20Sustainability\%20A\%20review\%20of\%20the\%20Evidence\%20 NCEPHWorkingPaperOctober2011x\%20(3).pdf

14. Chernev, A. (2004). Goal-Attribute Compatibility in Consumer Choice. Journal of Consumer Psychology, 14(1\&2), pp. $141-150$.

15. Cheval, B. Audrin, K., Sarrazin, P., \& Pelletier, L. (2017).When hunger does (or doesn't) increase unhealthy and healthy food consumption through food wanting: The distinctive role of impulsive approach tendencies toward healthy food. Appetite, pp. 116, 99-107. 
16. Galli, A., Iha, K., Halle, M., Grunewald, N., Eaton, D., Capone, R., Debs, P., \& Bottalico, F. (2017). Mediterranean countries' food consumption and sourcing patterns: An Ecological Footprint viewpoint. Science of The Total Environment, pp. 578, 383-391.

17. Gonzalez Fischer, C., Garnett, T. (2016). Plates, pyramids, planet. Developments in national healthy and sustainable dietary guidelines: a state of play assessment. FAO and the Environmental Change Institute \& The Oxford Martin Programme on the Future of Food. Food and Agriculture Organization of the United Nations, The Food Climate Research Network at The University of Oxford, 2016. http://www.fao.org/3/a-i5640e.pdf

18. Grieger, J., Wycherley, T., Johnson, B., \& Golley, R. (2016). Discrete strategies to reduce intake of discretionary food choices: a scoping review. International Journal of Behavioral Nutrition and Physical Activity. URL https://ijbnpa. biomedcentral.com/articles/10.1186/s12966-016-0380-z

19. Hadjikakou, M. (2017). Trimming the excess: environmental impacts of discretionary food consumption in Australia. Ecological Economics, pp. 131, 119-128.

20. Johnson, B, Hendrie, G, Golley, R. (2016). Reducing discretionary food and beverage intake in early childhood: a systematic review within an ecological framework. Public Health Nutrition,19(09), pp.1684-1695.

21. Katona, G. (1975). Psychological economics, Elsevier Scientific Publishing Company, New York. p. 438.

22. Nansel, T.R., Lipsky, L.M., Eisenberg, M, H, Haynie, D.L., Liu, D., \& Simons-Morton, B. (2016). Greater Food Reward Sensitivity Is Associated with More Frequent Intake of Discretionary Foods in a Nationally Representative Sample of Young Adults. Front. Nutr., pp. 3-33.

23. Ruopeng, An (2016). Beverage Consumption in Relation to Discretionary Food Intake and Diet Quality among US Adults, 2003 to 2012. Academy of Nutrition and Dietetics, 116(1), pp. 28-37.

24. Tassielli, G., Renzulli, P. A., Castellani, V., Sala, S. (2017). Environmental impacts of food consumption in Europe. Journal of Cleaner Production, pp. 140, 753-765. 